\title{
EDITORIAL
}

\section{An approach to dark circles under the eyes}

\author{
Shahin Aghaei \\ Iran University of Medical Sciences, Tehran, Islamic Republic of Iran
}

Keywords: Infraorbital darkening, periorbital darkening, dark circles, eyes, treatment, therapy

Citation: Aghaei S. An approach to dark circles under the eyes. J Surg Dermatol 2016; 1(2): 55-56; http://dx.doi.org/10.18282/jsd.v1.i2.67.

Correspondence to: Shahin Aghaei, Roonik Skin Clinic, \#78, Asad-abadi Ave., Tehran, Islamic Republic of Iran, shahinaghaei@yahoo.com

Received: $12^{\text {th }}$ July 2016; Published Online: $29^{\text {th }}$ July 2016

$\mathrm{W}$ ho does not loath looking in the mirror after a long and sleepless night? Periorbital melanosis, popularly known as "dark circles" (DC) under the eyes, is a common and frustrating cosmetic grievance in both men and women, although in most cases it is not a sign of a severe medical condition ${ }^{[1,2]}$. DC is inevitably a sign of exhaustion, but anxiety seems to deteriorate facial appearance through the development of $\mathrm{DC}^{[3]}$.

There has been little research dedicated to investigating the cause of this common disorder. The fact that various treatment modalities carried out in the past resulted in inconsistent outcomes shows that pinpointing the cause of DC is not exactly a walk in the park. There are multiple factors that cause DC in a majority of patients. Possible reasons include excessive pigmentation, along with thin and luminous lower eyelid skin overlying the orbicularis oculi muscle. As people grow older, the skin gets thinner and collagen fibers are lost, at times augmenting the advent of tiny blood vessels beneath the eyes, thus making the area seems darker. While lack of sleep and aging certainly play a role in under-eye discoloration, so do genetics, allergies, hormonal abnormalities, and accumulated skin damage ${ }^{[4,5]}$.

Certain conditions such as fluid disproportion or locally swollen eyelids can also cause shades that make the area under the eyes seem darker. Some researchers also speculated that DC has a tendency to run in families. Brown circles could also form as a result of hyperpig- mentation triggered by chronic eye-rubbing, sun exposure, or genetics. When there is no apparent cause, it could be due to termed idiopathic cutaneous hyperchromia of the orbital region $(\mathrm{ICHOR})^{[6]}$. Numerous treatments have been used for this complaint with various results, including topical lightening creams, chemical peelings, lasers, and even fat injections. None of the treatments have proven to be uniformly effective and thus there is a need for newer approaches ${ }^{[7-9]}$.

In spite of its prevalence and cosmetic importance, there are only a few reported works in literature regarding DC. A virtuous description of this condition is unavailable and there is neither an overall understanding about the pathogenesis nor an agreement about the main factors responsible for it. Treatment modalities are chosen in empirical ways, frequently resulting in suboptimal outcomes. It is important to identify the probable cause and choose appropriate treatment methods.

DC is less responsive to standard treatments due to its multifactorial etiology and the presence of melanin in skin layers. Nevertheless, even a mild-to-moderate improvement in appearance can enhance the quality of life of patients; hence topical therapies and simple physical therapies can be used to treat patients seeking to improve the cosmetic appearance of their eyes ${ }^{[10]}$. Instead of fighting an uphill battle against the genes, one can also turn to corrective coloring makeup.

Copyright (C) 2016 Aghaei S. This is an Open Access article distributed under the terms of the Creative Commons Attribution-Non Commercial 4.0 International License (http://creativecommons.org/licenses/by-nc/4.0/), permitting all non-commercial use, distribution, and reproduction in any medium, provided the original work is properly cited. 


\section{Conflict of interest}

The author declared no potential conflict of interest with respect to the research, authorship, and/or publication of this article.

\section{References}

1. West TB, Alister TS. Improvement of infraorbital hyperpigmentation following carbon dioxide laser resurfacing. Dermatol Surg 1998; 24(6): 615-616. doi: 10.1111/j.1524-4725.1998.tb04216.x.

2. Sheth PB, Shah HA, Dave JN. Periorbital hyperpigmentation: A study of its prevalence, common causative factors and its association with personal habits and other disorders. Indian J Dermatol 2014; 59(2): 151157. doi: 10.4103/0019-5154.127675.

3. Roberts WE. Periorbital hyperpigmentation: Review of etiology, medical evaluation, and aesthetic treatment. J Drugs Dermatol 2014; 13(4): 472-482.

4. Freitag FM, Cestari TF. What causes dark circles under the eyes? J Cosmet Dermatol 2007; 6(3): 211-215. doi: 10.1111/j.1473-2165.2007.00324.x.

5. Verschoore M, Gupta S, Sharma VK, Ortonne JP. Determination of melanin and haemoglobin in the skin of idiopathic cutaneous hyperchromia of the orbital region (ICHOR): A study of Indian patients. J Cutan Aesthet Surg 2012; 5(3): 176-182. doi: 10.4103/0974-2077.101371.

6. Huang YL, Chang SL, Ma L, Lee MC, Hu S. Clinical analysis and classification of dark eye circle. Int $\mathrm{J}$ Dermatol 2014; 53(2): 164-170. doi: 10.1111/j.13654632.2012.05701.x.

7. Kontochristopoulos G, Kouris A, Platsidaki E, Markantoni $\mathrm{V}$, Gerodimou M, et al. Combination of microneedling and $10 \%$ trichloroacetic acid peels in the management of infraorbital dark circles. J Cosmet Laser Ther 2016; 18(5):289-292. doi: 10.3109/14764172.2016.1157363.

8. Sahni K, Kassir M. Dermafrac ${ }^{\mathrm{TM}}$ : An innovative new treatment for periorbital melanosis in a dark-skinned male patient. J Cutan Aesthet Surg 2013; 6(3): 158-160. doi: 10.4103/0974-2077.118420.

9. Hassan AM, Hassan GFR, Aldalies HY, El Maghraby GM. Treatment of periorbital dark circles: Comparative study of chemical peeling with a combination of trichloroacetic acid and lactic acid versus carboxytherapy. J Surg Dermatol 2016; 1(2): 108-115. doi: 10.18282/jsd.v1.i2.29.

10. Sarkar R, Ranjan R, Garg S, Garg VK, Sonthalia S et al. Periorbital hyperpigmentation: A comprehensive review. J Clin Aesthet Dermatol 2016; 9(1): 49-55. 